\title{
EL REALISMO COGNOSCITIVO EN SANTO TOMÁS DE AQUINO. SUS CONDICIONES METAFÍSICAS ${ }^{1}$
}

MAURICIO BEUCHOT

INSTTTUTO DE INVESTIGACIONES FILOSÓFICAS

UNAM

\section{Planteamiento del problema critico}

Según nos dice el historiador de la ġnoseología Joseph Maréchal, ${ }^{2}$ ya en los griegos y en los medievales -en cuanto que sufrieron corrientes de fuerte escepticismo- hubo propiamente una crítica del conocimiento, aunque ciertamente no como la que conocemos en Descartes y Kant, por ejemplo. Sin embargo, no puede hablarse - como muchos han pretendido- de un realismo ingenuo en los medievales, como Tomás de Aquino; había toda una teoría del conocimiento que intentaba dar cuenta del fenómeno del conocer. Es decir, había un realismo crítico o "metódico", un esfuerzo por superar la cuestión que pusiera en tela de juicio el realismo cognoscitivo por parte de cualquier movimiento escéptico de ese tiempo-que culminaría en el criticismo. $^{3}$

Así, aunque no es el problema principal para Santo Tomás de Aquino, en su sistema hay elementos que nos ayudan a elaborar respuestas al problema crítico. $\mathrm{Y}$ por eso pensadores que estudian la filosofía tomista después de Descartes, creen que es posible y válido abordar el problema crítico-gnoseológico con elementos tomados de Santo Tomás. Es lo que trataremos de hacer ahora.

Entendemos aquí por realismo tomista lo siguiente: Santo Tomás admite la existencia de un mundo real, independiente del pensamiento y cognoscible por él. Esta es la tesis principal del realismo que sostiene. Pues bien, el realismo se topa con dos problemas que debe sortear ya desde el comienzo:

1 Este trabajo fue presentado en una de las sesiones de seminario de investigadores del Instituto de Investigaciones Filosóficas y se ha beneficiado de los comentarios de la persona que fue replicante en eșa ocasión, Ana Rosa Pérez Ransanz.

${ }^{2}$ Cfr. J. Maréchal, El punto de partida de la metafisica, Gredos, Madrid, vol. I, 1957, pp. 276 ss.

3 Cfr. E. Gilson, Réalisme thomiste et critique de la connaisance, Vrim, París, 1947, pp. 175 ss. 
(a) el de una fácil postulación dogmática de la validez del conocimiento y (b) el de enredarse sin más en una argumentación trascendental a partir de la cual nunca logrará apoyar lo que intenta, es decir: con ella jamás podrá pasar de lo epistemológico a lo ontológico de manera válida. Por ello es preciso ubicarse en una postura distinta, pero que esté exenta de ese dogmatismo cómodo ya de entrada y que, además, revista algunos caracteres de la argumentación trascendental, a saber, que provea un análisis del proceso cognoscitivo que venga a ser como la argumentación para apoyar esa postura realista. Este otro camino tendría que ser el análisis detallado y profundo de todos los actos que entretejen el conocer. Mediante ese análisis del proceso cognoscitivo se tratará de lograr que lo que se hace in actu excercito (o en acto ejercido, a saber, la actividad cognoscitiva) se recupere in actu signato (o en acto significado, a saber, con conciencia reflexiva de lo que se hace en dicha actividad cognoscitiva). Puesto en palabras más actuales, sería, como diría Habermas, una reconstrucción teórica de un proceso práctico; o, en palabras de Ryle, hacer que lo que pertenece al saber como (knowing how) se vuelva saber que (knowing that). Pero, ya que no podemos hacer esto ahora con detenimiento, por lo menos expondremos lo más esencial de las cọndiciones que exige Santo Tomás para poder decir que hemos llegado a la verdad (o a la posesión de la realidad) en nuestro proceso de conocimiento. Veamos, pues, esas condiciones de la verdad del pensamiento o del saber.

\section{El juicio como portador de la perdad}

Pero, antes que nada, señalemos cuáles son, según Santo Tomás, los portadores de la verdad, aquellos a los cuales puede aplicárseles del modo más propio el predicado "es verdadero". Él dice que son los juicios y éstos son los actos de conocimiento que se expresan en oraciones o enunciados. Son, así, los juicios actos o episodios mentales; son los que propiamente captan la verdad, y las oraciones o enunciados son sus signos; por ello, los juicios son propiamente portadores de la verdad, y las oraciones o enunciados sólo en tanto que signos de los juicios.

Hablando muy grosso modo, de acuerdo con Santo Tomás el conocimiento recorre tres niveles: el de los sentidos, el del intelecto directo o simple aprehensión (o conceptualización), y el del intelecto reflejo, o juicio y raciocinio. Pues bien, de una manera no mecanicista y unívoca, sino dinámica y analógica, la sensación a prepara la intelección directa, y ésta a la intelección refleja, en el sentido de que cada una de ellas aporta los elementos de la subsiguiente. Y es en este nivel más elevado, de la intelección refleja, en el que se da el juicio, y en él se ubica propiamente la verdad, el conocimiento realista, según esa idea de la verdad como correspondencia entre intelecto y objeto que profesaba Santo Tomás. 
Para Santo Tomás, pues, el asiento de la verdad es el juicio. El juicio es formalmente la sede de la verdad en el sentido de que sólo él versa sobre la esencia y la existencia de las realidades (el concepto versa sobre la esencia únicamente) y sólo en él se capta que se conoce la realidad, i.e. en él sabemos que conocemos o por lo menos (adoptando una expresión que usa Luis Villoro) ${ }^{4}$ creemos que sabemos que conocemos. Dicho con otras palabras, sólo en el juicio - $\mathrm{y}$ no en otro acto de la mente- podemos, por reflexión sobre nuestro contenido cognoscitivo de juicio, saber que corresponde a la realidad.

Por esa reflexión de la inteligencia sobre sí misma, para ver si, y cómo, capta la verdad, es por lo que dice Santo Tomás que la diferencia entre el apetito (o deseo) y la inteligencia estriba en que "el término del apetito, que es el bien, está en el mismo intelecto". 5 No consiste, pues, la verdad sólo en que el intelecto se conforme a un hecho, sino además en que el intelecto conozca que se conforma a un hecho. Como lo expresa Villoro: “ $S$ sabe que $p$ si y sólo si: (i) $S$ cree que $p$ y (ii) $S$ tiene razones objetivamente suficientes para creer que $p . " .6$

Esto es algo que no pueden hacer - de acuerdo con Santo Tomás- los sentidos (saber que conocen), sino sólo el intelecto, y lo hace en el juicio. Sólo en él se capta la conformidad misma del intelecto con la cosa: "Por lo cual, conocer esta conformidad [del intelecto con la cosa] es conocer la verdad. $Y$ ésta de ningún modo la conoce el sentido: pues aunque la vista tiene la semejanza de lo visible, sin embargo, no conoce la comparación que hay entre la cosa vista y aquello que él mismo aprehende de ella. En cambio, el intelecto puede conocer su conformidad con la cosa inteligible: mas, sin embargo, no la aprehende en cuanto conoce de algo lo que es [i.e. en la simple aprehensión del intelecto directo], sino cuando juzga que la cosa se da tal como es la forma que aprehende de la cosa; entonces de manera primordial conoce y dice la verdad. ${ }^{77}$ Por lo tanto, para Santo Tomás la verdad o el conocimiento de la realidad no se da en los sentidos ni en el intelecto directo, pues no reflexionan sobre su conocimiențo, sino en el intelecto reflejo o reflexivo, que, en el juicio, no sólo capta la esencia y la existencia de la cosas, sino que éstas son como él las conoce.

En suma, ¿qué es, para Santo Tomás, juzgar? Es el acto por el cual el intelecto compone (i. e. afirma) o divide (i.e. niega) conceptos entre sí (i. e. sujeto y predicado). Realiza una sintesis de los conceptos obtenidos en la aprehensión del intelecto directo. Más, "el acto de juicio -como explica bien Bernard Lonergan - no es solamente una síntesis, sino que es también la posición de

4 Cfr. L. Villoro, Creet, saber, conocer, Siglo XXI, México, 1982, p. 209.

5 Sto. Tomás, Summa Theologiae, I, q. 16, a. 2, c.

6 L. Villoro, op. cit., p. 175.

7 Sto. Tomás, Summa Theologiae, I, q. 16, a. 2. c. 
una síntesis ${ }^{\$}{ }^{8}$ Tal posición o aseveración incluye el saber que la síntesis es verdadera, que incluye el decir de ella: “así es". (Por ello puede decirse que Santo Tomás en cierta forma acoge la teoría de Frege de que la verdad es un predicado de todos los juicios verdaderos.)

Ahora bien, en el acto de juicio desembocan todos los demás actos: tanto la sensación como la intelección directa o simple. Aunque sólo en el juicio se da formalmente la verdad, en ellos se da materialmente o de modo fundamental. Y en el juicio se reúnen además dos aspectos explicativos o puntos de vista: por un lado el gnoseológico, y por otro lado el ontológico. El punto de vista gnoseológico son propiamente los actos que se pueden discernir en el proceso del acto judicativo, de modo que se vea cómo se llega al conocimiento de la verdad y cómo se llega a saber que se conoce la verdad. El punto de vista ontológico consiste en el establecimiento de algunas entidades inferidas (de tipo mentalista) que se aducen para explicar el hecho del conocimiento judicativo: tales entidades (mentales) inferidas son las "especies" o "verbos mentales". Podemos decir que el aspecto gnoseológico del problema del conocimiento judicativo explicita las condiciones formales de la verdad y que el aspecto ontológico explicita las condiciones "materiales" de la misma. Hablaremos primero de las condiciones formales o propiamente gnoseológicas de la verdad y luego de las condiciones materiales y ontológicas. Con ellas se tendrá una fundamentación reflexiva del realismo.

\section{Las condiciones formales del saber: la intelección refleja o el juicio}

¿Cómo sabemos que un juicio es verdadero, que refleja la realidad? Hemos dicho que para Santo Tomás el juicio es la posición de una síntesis de conceptos, afirmativa o negativa y, por lo mismo, susceptible de valor de verdad. ¿Cómo sabemos si un juicio es verdadero o falso?, ¿cómo sabemos su valor de verdad? El valor de verdad, en el tomismo, se determina con base en la correspondencia o "semejanza" del entendimiento con el objeto. Y tal determinación se hace mediante la reflexión: con ella el intelecto ve si hay o no correspondencia entre su juicio y la realidad, para decir que es verdadero.

Es decir, el intelecto aporta razones para decir que es verdadero su juicio, para garantizar que "sabe que $p$ ". Lo hace mediante otros juicios que son las razones que ofrece para apoyar su juicio. Pero esto no desencadena un regresión infinita: ya el mismo Aristóteles decía que en la línea de las pruebas o razones, tanto como en la de las causas, hay un tope, pues de lo contrario nada existiría y nada sería tampoco concebible. ${ }^{9}$ En la línea de las razones,

8 B. Lonergan, La notion de verbe dans les écrits de Saint Thomas d'Aquin, Beauchesne, París, 1966, p. 60.

9 Esto lo recoge Sto. Tomás en De veritate, q. 1, a. 1, donde dice: No se puede proceder infinitamente en la serie de las proposiciones demostrables." 
el tope son los principios, hasta el principio de no-contradicción; en la de las causas, está el objeto mismo, que causa nuestra aprehensión cognoscitiva. Es un doble criterio con el cual se ha de contrastar y medir el juicio para saber si es verdadero: el criterio es tanto sensible como intelectual. No es la cosa en sí, a la que desconocemos y más bien hemos de probar, ni tampoco sabemos si sólo hay intelecto. Lo que sabemos es que, enfocada hacia el objeto, la intencionalidad de nuestro intelecto lo rebasa y pugna más allá de él. Tal criterio se encuentra en una doble resolución del juicio: (i) a los principios intelectivos y (ii) a lo sensible via la imagen.

Por una parte, pues, el criterio se encuentra en los principios del mismo intelecto. ${ }^{10}$ Para decir que tengo un verdadero saber de lo real, tengo que poder aducir - como dice Villoro- las razones objetivamente suficientes para tener ese juicio o aserto como verdadero y, por lo tanto, saberlo.

Pero también -en la línea empírica - el criterio es el objeto; nuestra intencionalidad cognoscitiva nos lanza del juicio a sus orígenes y causa, es decir, nos impulsa a su base empírica a través de la imagen, que es por así decir el soporte sensible y el apoyo experiencial del juicio. Al ejercer la intelección directa, simple, abstraemos del tiempo y el espacio y demás condiciones individuantes de lo concreto, y hacemos la resolución a los principios de manera concreta: vemos cómo éstos se aplican a la situación concreta que juzgamos, hacemos un raciocinio que parte de lo abstracto/universal (principios) y culmina en lo concreto/particular (juicio de hecho). ${ }^{11} \mathrm{Y}$ en ese punto podemos hacer la reflexión que nos indique si las condiciones o razones de nuestro juicio se cumplen.

La actividad argumentativa, entonces, con la que comprobamos un juicio, es como un círculo que parte de lo concreto, se eleva a lo abstracto (los principios) y vuelve a lo concreto (hasta el objeto mismo); y quien al juzgar sobre un hecho se desliga de lo concreto, corre el peligro de errar. Así, como decíamos, la verdad del juicio no sólo depende de razones objetivas con las que lo vamos probando en el orden intelectivo del raciocinio, sino que también depende de la otra resolución, que es a lo sensible. Todavía no estamos suponiendo el objeto sensible como cosa, sino como dato al que hay que mirar para contrastar con él el contenido del juicio que estamos comprobando.

Es donde hemos de tener acceso al mundo real, desde la intencionalidad cognoscitiva del sujeto. Para ello hay que saber diferenciar el sujeto y el objeto, saber reconocer al uno y al otro, y para distinguirlos se requiere haber hecho varios actos de juicio. En efecto, Santo Tomás plantea la necesidad de ubicar el sujeto: "La verdad, en efecto, sigue a la operación del entendimiento en tanto que el juicio de éste se refiere a la cosa tal como ella es; pero la verdad es

11 Sto. Tomás, Contra Gentes, 1. II, c. 96, ad finem. 
conocida por el entendimiento en tanto que reflexione sobre su propio acto; y no sólo en tanto que conoce su acto, sino en tanto que conoce su adecuación a la cosa, adecuación que no puede ser conocida si no se conoce la naturaleza del mismo acto; y, por su parte, esto último tampoco puede ser conocido si no se conoce la naturaleza del principio activo, que es el mismo entendimiento, a cuya naturaleza le compete el acomodarse a las cosas. Luego el entendimiento conoce la verdad en tanto que reflexiona sobre sí mismo. ${ }^{\$ 12}$ En el lado gnoseológico del juicio, pues, sabemos si es verdadero cuando aportamos razones objetivas suficientes para garantizarlo y cuando, por reflexión, somos capaces de distinguir el sujeto del objeto y decidir si lo que juzgamos pertenece sólo al sujeto o corresponde también a algo objetivo en la realidad. El dar razones objetivas nos abre a la intersubjetividad, por la que compartimos el conocimiento con una comunidad epistémica. Pero es por la reflexión como buscamos la correspondencia de lo subjetivo con lo objetivo.

Y cuando hablamos de "subjetivo" y "objetivo" es porque ya hemos hecho la distinción, después de muchos actos de conocimiento. Pues antes de ello no puede hacerse. En efecto, supongamos que tengo un dato sensible. ¿Cómo puedo decir que es sujeto o que es objeto? Sólo creando la posibilidad de distinguir una cosa y otra (i. e. lo subjetivo y lo objetivo, o el sujeto y el objeto). Y esto requiere el surgimiento de la idea del yo (por opcsición a la cual pueda surgir la del no-yo o del mundo externo). Pero tal idea del yo no es inmediata. Si hemos de creer a los psicólogos genetistas y a los psicoanalistas, la idea del yo se va construyendo poco a poco. ¿Quiere esto decir que primero se capta algo del lado de la realidad objetiva? No, puesto que la idea de objeto requiere la de sujeto. Entonces, se comienza con un dato amorfo y neutro, que no es ni subjetivo ni objetivo. Y se empieza a diferenciar a medida que captamos más cosas y las comparamos entre sí y con nosotros, y a medida que hurgamos los efectos de unas y de otras, encontrando su relación con nosotros mismos, éxitos y fracasos prácticos, etc. Todo ello nos habla del carácter reflexivo de la teoría del conocimiento (como el de la filosofía en general); y entonces todo reside en la interpretación del resultado de esa reflexión: el dato está de mi lado como sujeto o está del lado del objeto. Un dato no se discute, pero la interpretación del mismo es lo que tiene que ser discutible (si no, la polémica carece de todo sentido). Y la interpretación tomista favorece el lado del objeto. Santo Tomás dice que lo primero que conocemos es el ente, o que todo lo conocemos bajo el aspecto de ente. ${ }^{13}$ Aun antes de saber si todo es subjetivo o hay ente real, sabemos que hay ente, sea éste de razón (i.e. pensado) o real, una especie de monismo. ¿Cómo distinguimos después de ello el ente en pensado y real? Allí es donde interviene la interpretación, y la

12 Id., De veritate, q. 1, a. 9, c.

13 Ibid., q. 1, a. 1, c. 
interpretación tomista, como dijimos, favorece al ente real y objetivo. Como dice Sertillanges: “[Para Santo Tomás] el conocer es objeto antes de ser sujeto; el primer conocido (primum cognitum) no es el conocedor como tal, sino el ser. [...] El hombre no se conoce sino en el acto de llegar a ser otro: el cognoscente en acto es lo conocido en acto (cognoscens in actu est cognitum in $a c t u)$, de suerte que el orden verdadero del conocer es éste: Primeramente el objeto, en segundo lugar el acto, en tercer término la potencia o facultad de donde procede el acto, cuarto y último el sujeto. ${ }^{\text {14 }} \mathrm{Y}$, también según dijimos, la interpretación del dato es la que ha de ser sujetable a discusión. Pero, ahora, ¿cómo se discute una interpretación (tan básica) de un dato? ¿Cómo se argumenta a favor de la interpretación subjetiva y de la interpretación objetiva? ¿Es incluso posible argumentar a ese nivel de principios? ¿Es posible siquiera la discusión?

Por lo menos tratemos de hacer ver los principios en los que Sánto Tomás apoya esta interpretación suya del hecho del conocer. $Y$ es donde ofrece una explicación ontológica del conocimiento. Son las "condiciones materiales" o "fundamentales", es decir, los supuestos ontológicos del conocimiento humano: las entidades teóricas que se infieren o se postulan para explicarlo.

\section{Sujeto, objeto y "especie" o semejanza mediadora entre ellos}

"Para Santo Tomás, conocer no consiste en recibir una impresión ni en producir una imagen; conocer es algo mucho más íntimo y mucho más profundo. Conocer es llegar a ser, llegar a ser el no-yo." 15 Pero no se trata de una identificación física del sujeto con el objeto, sino inmaterial, a través de una "especie" (species) o semejanza mental que los une intencionalmente. Por esa intencionalidad, conocer es llegar a ser inmaterialmente eso otro, en cuanto otro. El cognoscente se apropia intencional y psíquicamente la esencia de lo conocido, se asimila a él con la inteligencia, sin por ello requerir una unión física, ya que la unión y la identificación se dan de manera inmaterial, intencional y psíquica. De esta forma el intelecto debe plegarse y obedecer a la realidad, que es la medida y criterio de su intencionalidad.

Pero el tomismo asigna nombres difíciles de captar (por los lectores contemporáneos) a los conceptos que están en juego en la explicación del conocimiento. El acto de conocimiento (o de captación), se nos dice, es una relación trascendental ${ }^{16}$ entre la facultad cognoscitiva y el objeto cognoscible. El co-

14 A.D. Sertillanges, Santo Tomás de Aquino, Desclée de Brouwer, Buenos Aires, 1945, t. II Pp. 118-119.

15 J. Maritain, El alcance de la razón, Emecé, Buenos Aires, 1959, p. 30.

16 Se llama en el tomismo (aunque no es nombre que usara Santo Tomás) "relación trascendental" a aquella relación que lo es impropiamente, dado que sus términos más bien están unidos, 
nocimiento es además una acción inmanente, ${ }^{17}$ en la que hay un agente y un paciente. El agente es el objeto y el paciente es la facultad. Efectivamente, el objeto impresiona a la facultad sensible y le deja una impronta o representación suya, una semejanza o copia en un dispositivo de conocimiento que es la semejanza o "especie" (species). La especie es una entidad mental o receptáculo psíquico (intencional) en el que se capta al objeto. Así, la especie es el medio que une a la facultad con el objeto. $Y$ es que el objeto no puede plasmarse ni entrar en la facultad tal como es, con su existencia material extramental; por eso entra y se plasma en ella con una existencia distinta: no material, sino psíquica, no con una existencia natural, sino intencional, cognoscitiva.

Pues bien, la especie es el mediador o vehículo en el que se plasma, se copia, se imprime la cosa o el objeto. La especie es una entidad psíquica, intencional, que sirve a la facultad cognoscitiva para atrapar y retener en sí misma la captación de las cosas. De esta manera, hay especies sensibles e inteligibles, según se trate del nivel sensorial o intelectual. (En los sentidos externos, se llama "especie sensible propia", y corresponde a cada uno de los cinco sentidos; en el sentido interno o sentido común, se llama "especie sensible común"; en la imaginación o fantasía se llama "imagen" o "fantasma"; en el intelecto posible se llama "especie inteligible", ya sea "impresa" o "expresa". ${ }^{18}$ Esta última (la especie expresa) es propiamente lo que se llama "verbo mental", el cual puede ser concepto o juicio. Y el verbo mental es la especie por excelencia. Por ello nos centraremos en él, sobre todo en el concepto, para ver cómo la teoría de la especie es la que salvaguarda el realismo tomista.)

Más aún, la especie o concepto no es sólo una semejanza sin más de la cosa, como etimológicamente parece insinuarlo. Es además la captación de la cognoscibilidad que la cosa tiene. En el plano empírico, la especie sensible es una copia (psíquica) exacta y fiel de la cosa; y después, en el plano imagi-

y sólo se trata de aspectos de la misma cosá que se ven como si fueran elementos de una relación; por ejemplo, la materia y la forma están unidas en el ente corpóreo, pero se dice que mantienen entre ellas una relación trascendental. Así también el cognoscente y lo conocido, mediante la especie cognoscitiva, están unidos en relación trascendental. Cfr. M.D. Philippe, "La notion de relation transcendentale est-elle thomiste?", Revue des sciences philosophiques et thelogiques, no. 42, 1958, pp. 265-275.

17 Los escolásticos dividían la acción en inmanente y transeúnte. La inmanente es la que no sale del sujeto, como el pensar y el querer del hombre; la transeúnte o transitiva es la que sale del sujeto o agente y se plasma en el objeto o paciente, como el cortar algo. Por eso la acción inmanente no ha de tomarse como acción en sentido estricto, sino más bien como algo perteneciente al género de la cualidad. Es más cualidad que acción, propiamente.

18 Santo Tomás, siguiendo a Aristóteles, distingue entre intelecto agente e intelecto paciente o posible. El primero tiene la función de obtener a partir de la imagen la especie impresa que se inscribe en el intelecto posible, y éste tiene la función de elaborarla como especie expresa o concepto. 
nativo, la imagen o fantasma es una semejanza basada en ella; y finalmente, en el plano intelectivo, la especie inteligible, sobre todo el concepto, es una presencia intelectiva de la cosa en la mente, basada en la imagen. Por tanto, si en la especie sensible se salvaguarda el realismo, por cierta transitividad se salvaguarda en la imagen, que se basa en lo sensible; y, si se salvaguarda el realismo en la imagen (así como se salvaguarda en lo sensible), también por cierta transitividad se salvaguarda en el concepto, que se basa en la imagen. $\mathrm{Y}$, en esta forma, por esa transitividad, se salvaguarda el realismo en todos los niveles del conocimiento. Y no opera aquí la objeción empirista, según la cual lo exacto es únicamente la percepción sensible y la idea o concepto es sólo una mala copia, una copia desvaída, de la sensación; pues en el tomismo la imagen no es una copia de la sensación ni el concepto es una copia de la imagen, sino que la imagen recoge de la sensación el núcleo imaginable de ésta, y el concepto recoge el núcleo inteligible o de la inteligibilidad de la imagen. (La inteligibilidad y la imaginibilidad se dan ya en lo sensible, sólo que en potencia, y al ser imagen y concepto, se recoge en ellos eso imaginable y eso inteligible respectivamente que hay en las cosas sensibles.) $\mathrm{Y}$ así, en lugar de aminorarse la cognoscibilidad, como ocurre en el empirismo, en el tomismo se vuelve más perfecto el conocimiento según se avanza más allá de los sentidos hacia la inteligencia.

De modo que, si entendemos - como en la metafísica tomista - que una cosa está compuesta de esencia y existencia, podemos decir que en la especie se capta la esencia de la cosa, y fuera de la mente esa esencia tiene una existencia física y material, y dentro de la mente esa misma esencia tiene una existencia psíquica e intramental; es decir, en la especie se da la esencia de la cosa con una existencia intencional, mientras que en la cosa real se da esa misma esencia con una existencia material. Y, como la esencia que se contiene intencionalmente en la especie es la misma que se da físicamente en la realidad fuera de la mente, se salvaguarda el realismo. ${ }^{19}$

\section{La "especie" como signo (formal)}

Pues bien, la especie cognoscitiva es un signo, como lo expresa Santo Tomás; ${ }^{20}$ más aún, es, como lo llaman los tomistas posteriores, un signo formal. Veamos qué es esta clase de signo. La noción tomista de signo es “aquello

19 La identidad entre la especie y la cosa no es absoluta, sino que es la identidad relativa que se da entre signo y objeto, por más que sea un signo formal y por ello más idéntico a la cosa que el signo instrumental. Cfr. J. Maritain, Distinguir para unir o los grados del saber, Club de Lectores, Buenos Aires, 1965, Pp. 604-605.

20 Cfr. Sto. Tomás, De veritate, q. 9, a. 4, ad 4. 
que representa a la facultad cognoscitiva algo diferente de sí mismo". ${ }^{21} \mathrm{Sig}$ nificar, pues, es representar, y representar es hacer conocer. Hacer conocer es influir causalmente en el conócimiento; representar es hacer presente algo a una facultad; $y$ significar es hacer presente algo distinto de sí a una potencia o facultad. Y ese presentar algo distinto a la potencia puede hacerse de dos maneras principales: de manera formal y de manera instrumental; por lo tanto, hay dos clases principales de signo: el formal y el instrumental.

El signo formal es el que representra algo distinto de sí, pero lo hace en sí mismo y disminuyéndose a sí mismo para-quúe resplandezca aquello otro. Por así decir, es un signo perfectísimo, ya qừe en él predomina la representación sobre todo otro aspecto. Si distinguimos en todo signo una parte de objeto y otra parte de signo propiamente dicho, en el signo formal la parte de objeto se oculta y sin discurso nos deja ver la parte de signo que tiene. No detiene o distrae la atención en su ser de objeto, sino que la centra en su ser de signo, mostrando en sí mismo lo significado. Ejemplos de este signo son las especies cognoscitivas, tanto, sensibles (percepción sensorial e imagen) como inteligibles (çonceptos). Este signo presenta de manera intencional lo que afuera de la mente se dà de modo real; presenta de manera psíquica lo que fuera de la mente se da de manera física. (La escolástica, que ve al ente como díada de esencia y existencia, diría que el signo formal presenta con una existencia intencional a la esencia que fuera de la mente tiene existencia real, o que presenta con existencia psíquica a la esencia que fuera de la mente tiene existencia física. En ambos casos se trata de la mismä esencia con diferente existencia; y, dado que es la misma esencia o modo de existir en cada caso, se preserva el realismo por la adecuada y fidedigna reprêsentaçión de la cosa por parte de la especie çognoscitiva.) El signo formal, èn resựmen, significa en sí mismo y por sí mismo, sin necesidad de un conocimiento previo de sí mismo como objeto (i. e. como objeto disminuye y se esconde para dejar que resplandezca en él y se muestre lo significado).

El signo instrumental, en cambio, es el que representa algo distinto de sí, pero a partir de un previo conocimiento de sí como objeto. No es un signo perfecto, como el anterior, pues su parte de objeto se interpone y atrae la atención sobre sí antes que hacia su significado. Su parte de objeto parece predominar sobre su parte de signo. O, por lo menos, su parte de signo no predomina tanto sobre su parte de objeto como en el signo formal. Ejemplos de signo instrumental son todos los signos exteriores a la mente, según los cinco sentidos (visuales, auditivos, olfativos, gustatives y táctiles), como la huella en el lodo representa el paso del animal, el humo representa al fuego,

21 J. de Sto. Tomás, Cursus Philosophicus, B. Reiser (ed.), Marietti, Taurini, 1930, vol. I, p. 9 a. 
el lenguaje representa a las cosas, etc. (Omitimos aquí otras divisiones que los escolásticos seguidores de Santo Tomás daban del signo.)

Ahora entendemos por qué la especie cognoscitiva (percepción, imagen o concepto) es signo formal, pues no es aquello que se conoce, sino aquello en lo cual y por lo cual se conoce la cosa. ${ }^{22}$ Descartes, al decir que la idea o concepto es lo que se conoce, la hacía un signo instrumental, pues su ser de objeto puede menoscabar su ser de signo y deformar o distorsionar la representación.

Hemos dicho que el signo tiene una parte de objeto. Esto puede aclararse un poco más con la teoría tomista de los objetos de conocimiento u objetos cognoscitivos. Hay tres tipos de objeto de conocimiento: (a) objeto sólo motivo, (b) objeto sólo terminativo y (c) objeto a la vez motivo y terminativo. $\mathrm{El}$ objeto terminativo es aquel en que el acto del conocimiento se termina, se aquieta y se detiene, p. ej., al ponerme a ver una pared, esa pared es el objeto terminativo de mi acto de visión. El objeto motivo es aquel que no detiene en sí la intencionalidad del conocimiento, sino que sólo lo hace pasar al conocimiento de otra cosa; es decir, el objeto sólo motivo mueve a la facultad a formarse una noticia, no de él mismo, sino representativa de otra cosa, como lo hace la imagen del emperador con respecto a la noticia del emperador. El objeto motivo y terminativo a la vez es el que mueve a la facultad cognoscitiva a formarse una noticia de él mismo, como cuando la imagen del emperador suscita a formarse una noticia o conocimiento de ella misma por sus cualidades artísticas. El objeto sólo motivo corresponde al signo, o al acto de significar, mientras que el objeto motivo y terminativo corresponde al representar; y no hay que identificar significar con representar, porque el segundo es más amplio que el primero. En efecto, representar es hacer presente, y una cosa puede hacerse presente o representarse a sí misma, en cuanto es objeto al mismo tiempo motivo y terminativo. En cambio, significar es hacer presente algo sólo como objeto motivo, pues nada es signo de sí mismo. La idea o concepto, entonces, sería un signo, i. e. un objeto sólo motivo, y no una mera representación, es siempre la representación de algo distinto de sí mismo. No tendría, pues, la teoría tomista del conocimiento tras de sí una metafísica de la representación, sino más apropiadamente de la significación. ${ }^{23}$ La idea o concepto es un signo, un signo formal, el cual se caracteriza porque, a diferencia del signo material o instrumental, no requiere ser conocido primero en su ser de objeto y después en su ser de signo o en lo que significa, sino que

22 Sobre esto, gfr. J.A. Casaubón, “Para una teoría del signo y del concepto mental como signo formal", Sapientia, no. 10, 1955, Pp. 270-283; J. González Pola, “Gnoseología de la idea en la escolástica”, Studium, no. 3, 1963, pp. 301-322; id. "Noción tomista del signo formal", ibid., no. 5, 1965, pp. 97-113.

${ }^{23}$ Cfr. J.D. Robert, "Note breve sur quelques conditions ontologiques du connâitre humain", Revue Philosophique de Loupain, no. 83, 1985, pp. 400-409. 
de inmediato nos hace conocer en sí mismo lo que significa, i. e. se oculta él mismo como objeto para mostrarse como signo o mostrar lo que significa. Así, el cuadro de una flor nos hace conocerlo primero a él mismo como objeto, con cualidades físicas y estéticas, y después de eso nos hace conocer lo que significa. En cambio, la especie sensible o inteligible de una flor no nos hace conocerla a sí misma como un objeto que es una especie sensible, sino que de inmediato y en sí misma nos hace conocer la flor, sin ningún conocimiento previo de ella misma como especie.

Tenemos, pues, que la especie cognoscitiva o concepto (i. e. la llamada por los tomistas "especie expresa") es un signo formal. La naturaleza del signo formal hará que se trate de un conocimiento apropiado y adecuado de lo que se conoce, fidedigno; a pesar de tener un carácter mediato e indirecto, es conocimiento reproductivo fiel, es una copia de la cosa, más aún, en la metafísica tomista es la misma esencia de la cosa con existencia intencional, mental o psíquica (la misma esencia que fuera de la mente tiene existencia física y material); y todo ello salvaguarda al realismo. En efecto, hemos visto que el signo formal es aquel en el que se conoce la cosa, sin que exija un conocimiento previo de ese signo en tanto que objeto. El signo formal es algo in quo, no per quod, cognoscitur aliquid, esto es, es algo en lo que se conoce lo significado, no tanto algo mediante lo cual se conoce lo significado. En cambio, el signo instrumental, que es la contraparte del signo formal, primero fija la atención en sí mismo como objeto, y después en sí mismo como signo, es decir, nos remite a lo que significa después de haberlo captado a él como objeto. 